\title{
Creating a Current Awareness Service Using Yahoo! Pipes and LibGuides
}

\section{Elizabeth Kiscaden}

\begin{abstract}
Migration from print to electronic journals brought an end to traditional current awareness services, which primarily used print routing. The emergence of Real Simple Syndication, or RSS feeds, and email alerting systems provided users with alternative services. To assist users with adopting these technologies, a service utilizing aggregate feeds to the library's electronic journal content was created and made available through LibGuides. Libraries can reestablish current awareness services using existing technologies to increase awareness and usage of library-provided electronic journal content. The current awareness service presented is an example of how libraries can build basic current awareness services utilizing freely accessible technologies.
\end{abstract}

\section{CURRENT AWARENESS SERVICES}

Library current awareness services, commonly referred to as "table of contents" services, historically involved the dissemination of information in the form of print journals or photocopied journal contents routed to library users subscribed to the service. ${ }^{1,2}$ These services have been particularly popular among corporate, law, and hospital libraries, which routinely route serials to primarily internal clients. While these paper-based services are still offered at some libraries, most shifted to an electronic model of service with the migration to electronic journals.

As libraries adopted electronic journals, many paper-based current awareness services transitioned to an electronic table of contents service utilizing email alerts or referred users to RSS feeds made available by publishers and database vendors. ${ }^{3} \mathrm{~A}$ common challenge to a library-managed electronic table of contents service is the complexity of managing alerts for hundreds of electronic journals for multiple patrons. More often, libraries make individual users responsible for subscribing to email alerts or RSS feeds on their own, effectively transferring the responsibility of subscribing to, filtering, and managing incoming information to the user.

A drawback to this migration is that library users often don't possess a clear understanding of what tools are available to create their own service. ${ }^{4}$ Formerly, journals may have arrived on a user's desk for perusal, yet now users are required to seek out information independently. Additionally, despite the number of discovery tools available, library users are often unaware of journals available in an electronic format through their library. ${ }^{5}$ Information management tools have become necessary in our current information environment; with the abundance of

Elizabeth Kiscaden (elizabeth-kiscaden@uiowa.edu), former Library Director at Waldorf College, is Head, Library Services, Hardin Library for the Health Sciences, University of Iowa, Iowa City. 
information available, keeping up-to-date with new information in a discipline can be overwhelming. Therein exists an opportunity for libraries-academic, special, and public - to revitalize current awareness services and build information management tools using aggregate feeds.

\section{DESIGN AND DESCRIPTION OF THE SERVICE}

At Waldorf College, the Luise V. Hanson Library created a current awareness service utilizing RSS feeds, with the intent to assist faculty with keeping up-to-date with newly published content in the library's electronic journal collection. The service, dubbed Info SOS, was designed to overcome two barriers to patron participation in feed services: the chore of subscribing to and curating multiple feeds and the lack of awareness of feeds and feed reader technology. Info SOS was piloted to faculty during the spring of 2014 and was accompanied by an informal questionnaire to collect feedback.

Info SOS is built on RSS, or "Really Simple Syndication" technology, one of the most prevalent tools for keeping current with new information published electronically. RSS has been available for more than a decade ${ }^{6}$ and many users - both patrons and library professionals-are using this technology. However, while powerful and freely accessible, RSS feeds have their limitations. Subscribing to and curating multiple feeds can become a burden.

To eliminate the chore of managing multiple feeds, Info SOS displays feed aggregates created using Yahoo! Pipes http://pipes.yahoo.com/pipes/). Aggregate feeds, or feeds comprising multiple RSS feeds, can be created using many tools available freely online, such as Feed Stitch, Feed Informer, Feedburner, and more. Yahoo! Pipes was chosen for this service primarily because it requires limited coding knowledge, ${ }^{7}$ yet the software provides a number of advanced functions for sorting and combining large groups of feeds. These advanced features became essential when building aggregate feeds for content from journal aggregators.

Yahoo! Pipes requires a user account (free of charge) before constructing pipes. The software combines and sorts information using a visual editor that resembles virtual plumbing, which is presumably why the software is called Pipes. To construct the aggregate feeds composing Info SOS, librarians used the Fetch Feed operator to combine individual RSS feeds into a single feed. Once combined, the service uses the Sort operator, which sorts the aggregated content by date. From the Sort operator, the content is connected to the Pipe Output, from which a single RSS feed is generated.

The strength of Yahoo! Pipes lies in the advanced tools available for manipulating feed content. For example, Pipes sorts feed content from database vendors by the date it is published to the feed, not the publication date of the article. If desired, aggregate feed creators can use the Rename and Regex operators to remove the article publication date from the description field and use it to sort the feed content. Another useful tool is the Union operator, which allows creators to string together larger bundles of feeds. 


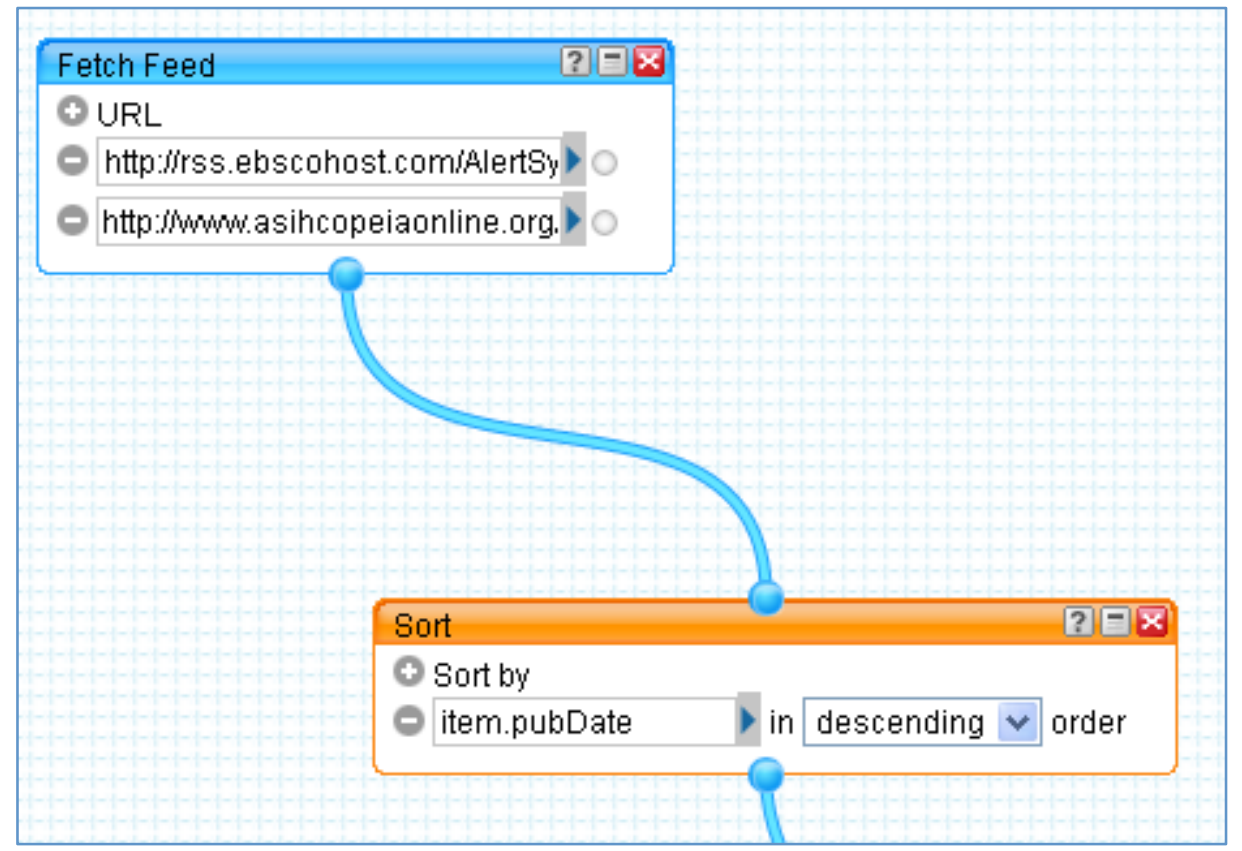

Figure 1. Fetch Feed and Sort Operator in Yahoo! Pipes

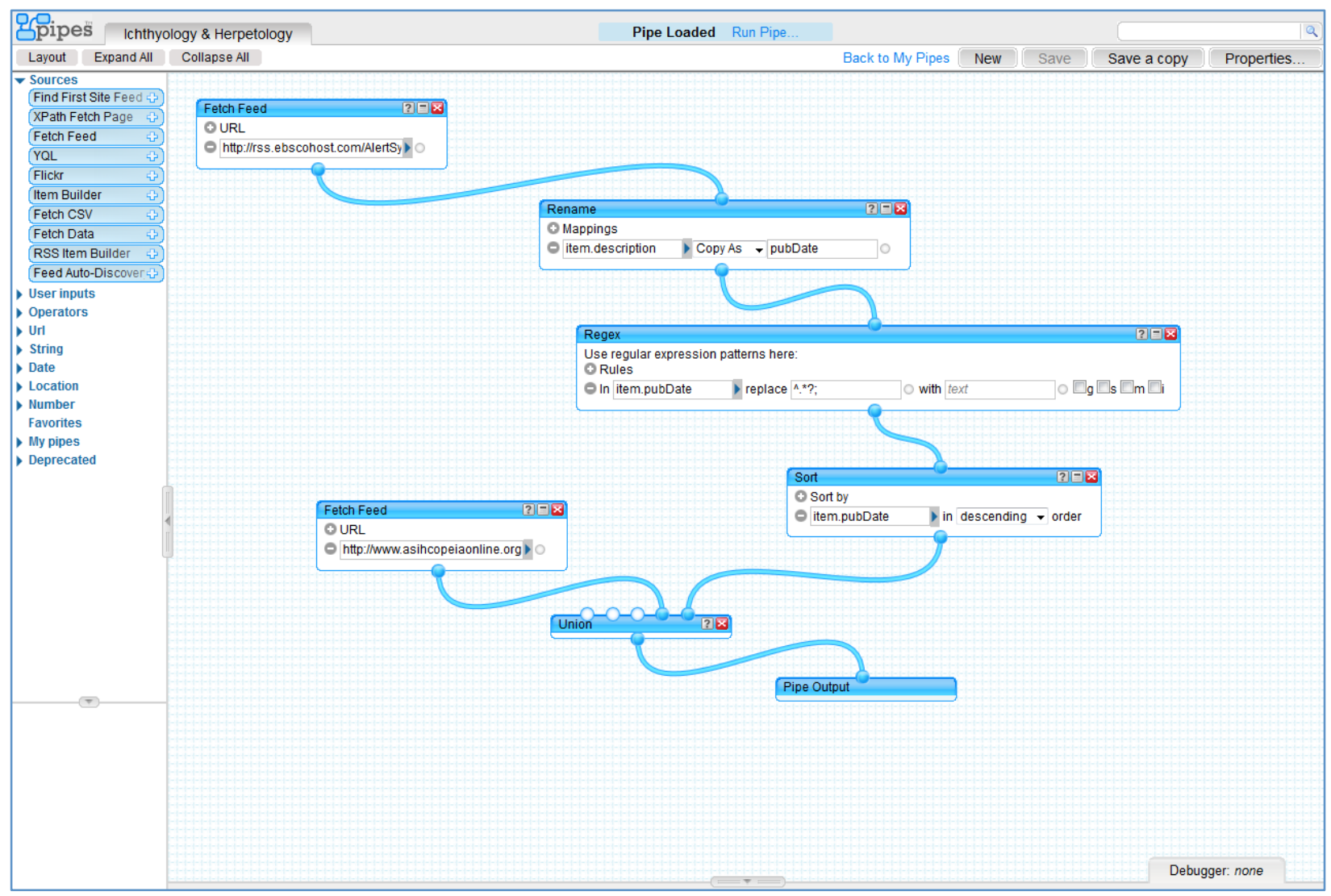

Figure 2. Image of Yahoo! Pipe Using Advanced Tools 
Lack of awareness is a barrier to user adoption of RSS feeds; many users have an unclear understanding of what a RSS feed is. If unfamiliar with RSS feeds, it is safe to assume that users are unfamiliar with RSS reader technology as well. At Waldorf College, this was confirmed by the questionnaire distributed during the pilot of this service. Of the twenty-eight faculty respondents, more than 70 percent had never used an RSS feed before using Info SOS. It is safe to assume that these faculty would not have a subscription to a feed reader.

Recognizing the need for an interface to deliver content, librarians used the LibGuides software to display content from these aggregate feeds. The software contains a tool for adding feed content, and allows for the application of an institution's proxy prefix to the URL, creating seamless access on and off campus. The Info SOS resource contains tabbed pages designated for individual fields (biology, psychology, library sciences, etc.) displaying aggregate feeds for journals in each subject area. For example, the physics page contains aggregate feeds for new articles published in the library's fulltext physics journals, as displayed in the figure below.

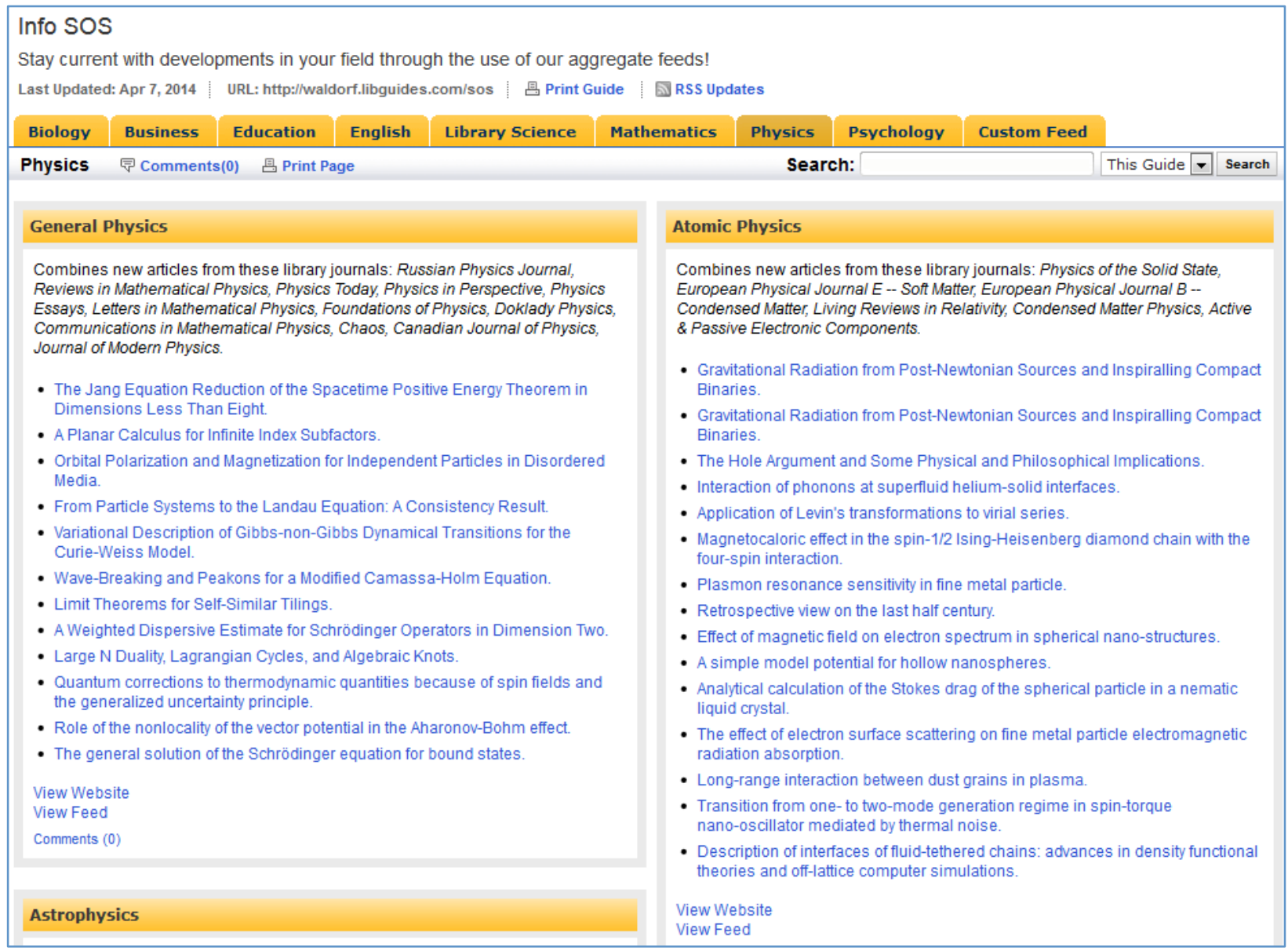

Figure 3. Aggregate Physics Feeds in LibGuides

\section{USER FEEDBACK}

Info SOS remains a relatively new service to library users at the Luise V. Hanson Library, but preliminary feedback has been positive. The service was advertised to faculty via email and 
accompanied by a feedback survey created using Google Forms. As stated previously, librarians received twenty-eight responses to the survey, a relatively strong response considering the limited number of faculty at the college.

Of the respondents, more than 70 percent had never used an RSS feed previously, instead using a variety of other tools to stay current with their field. Of those other tools, 18 percent of faculty subscribed to table of contents alerts, 27 percent browsed new issues of print journals, 25 percent visited association websites, and 23 percent conducted periodic searches for information in the library databases. It was of some concern that of these tools, only faculty using databases and subscribing to table of contents alerts would be connecting with the library's electronic journal collection.

When presented with Info SOS and asked whether faculty would find this tool useful, more than 70 percent responded that they would. Faculty were solicited for suggestions for improving the resource, and librarians received many suggestions for expanding the content. This feedback was valuable in that it provided justification for continuing the service beyond the pilot and a list of potential subject areas to begin expanding the service. The intended outcome of the service is to assist faculty in keeping current with literature in their field and utilizing the library's resources in the process.

\section{LIMITATIONS AND CHALLENGES}

Generating feeds from popular library databases, such as EBSCOhost and ProQuest, is limited in that the publication dates for articles are contained in the description field. This can make the Sort operator in Yahoo! Pipes somewhat inaccurate because it would be sorting by the date they were published to the feed, not by actual publication date of the journal article. If necessary, this issue can be corrected using the Rename and Regex operators by copying the item description as the publication date.

An additional challenge regarding vendor-created feeds relates to the issue of expiring feeds created from library databases. A library profile was required for each database, such as EBSCOhost or ProQuest, to create and save feeds. This allows for the renewal of expiring feeds; the email account attached to the profile receives an invitation to renew expiring feeds. Most vendors allow for feeds to be created at the database without a profile, but those feeds will automatically expire if not used within a period of time. The potential of feeds expiring may add an element of maintenance to the current awareness service.

\section{FUTURE DEVELOPMENTS}

Yahoo! Pipes offers the unique ability to publish pipes that others may share and "clone." For libraries interested in creating aggregate feeds for popular EBSCOhost journals, the pipes created for Info SOS are available to clone at http://pipes.yahoo.com/infosos. A search of published pipes available in Yahoo! Pipes reveals pipes created by many public and academic libraries, all of which are available to clone and edit. The ability to share pipes with other institutions introduces the possibility of current awareness services shared between library consortia or associations. 
As information becomes more abundant, tools and services to manage incoming information will continue to be a corresponding need. Creating and sharing services that utilize technology common to libraries presents us with the opportunity to collaborate with one another and revitalize libraryengineered current awareness services. These services offer a value that is twofold: library users benefit from the ability to stay current with publications in their field, and libraries have the potential of increased usage of their purchased content. With no financial investment, an aggregate feed-based service is a value that a variety of libraries can implement with the investment of only limited personnel time.

\section{REFERENCES}

1. G. Mahesh and Dinesh Kumar Gupta, "Changing Paradigm in Journals Based Current Awareness Services in Libraries," Information Services \& Use 28, no. 1 (2008): 59-65, http://dx.doi.org/10.3233/ISU-2008-0555.

2. Stephen M. Johnson, Andrew Osmond, and Rebecca J. Holz, "Developing a Current Awareness Service Using Really Simple Syndication (RSS)," Journal of the Medical Library Association 97, no. 1 (2009): 51-53, http://dx.doi.org/10:3163/1536-5050.97.1.011.

3. Mahesh and Gupta, "Changing Paradigm in Journals Based Current Awareness Services in Libraries."

4. M. Kathleen Kern and Cuiying $\mathrm{Mu}$, "The Impact of New Technologies on Current Awareness Tools in Academic Libraries," Reference \& User Services Quarterly 51, no. 2 (2011): 92-97.

5. Sandra J. Weingart and Janet A. Anderson, "When Questions Are Answers: Using a Survey to Achieve Faculty Awareness of the Library's Electronic Resources," College \& Research Libraries 61, no. 2 (2000): 127-34, http://dx.doi.org/10.5860/crl.61.2.127.

6. Jim Doree, "RSS: A Brief Introduction," Journal of Manual \& Manipulative Therapy 15, no. 1 (2007): 57-58.

7. Bill Dyszel, “Create No-Code Mashups with Yahoo! Pipes,” PC Magazine 26, no. 21/22 (2007): 1035. 